\title{
The Theory of Practice and Prospect of the Low Carbon City Planning
}

$$
\text { Jun } \mathrm{Ma}^{1, \mathrm{a}} \text {, Shengxiao } \mathrm{Li}^{1, \mathrm{~b}} \text { and Pengcheng Wang }{ }^{2, \mathrm{c}}
$$

${ }^{1}$ Architectural Design and Research Institute, Shenyang Jianzhu University, Shenyang, 110168, China P.R.

${ }^{2}$ College of Civil Engineering, Shenyang Jianzhu University, Shenyang, 110168, China P.R.

$$
\text { awyasyn@163.com , }
$$

\section{Keywords:Low carbon city, Urban planning, Theory, Practice, Prospect}

Abstract. This paper analyzes the relationship of low carbon city and climate change on the background of global warming. Low carbon city construction is the important measures to mitigate climate change crisis. And low carbon urban planning is a key technology of low-carbon urban construction. Research from three aspects of the low carbon urban planning theory, the concept and practice low(zero) carbon community, low carbon city development in the future.Sum up the low carbon urban planning research progress for domestic and overseas.Put forward the future trend of low carbon urban planning research aspects of the demarcation and path of low carbon city, low carbon urban planning and construction, the popularity of low-carbon technologies,enforcement mechanism innovation, low-carbon city construction.

\section{Introduction}

EEA as sessment report released in March 2009, nearly one hundred years, the earth's temperatures continue to rise, in 2008 the average global temperature is the early stage of the industrialization increased by $0.7{ }^{\circ} \mathrm{C}$. China and the general trend of the global climate warming. According to observation results released by the China meteorological administration.China over the past century surface average temperature increased by $1.1{ }^{\circ} \mathrm{C}$. According to the IPCC projections suggest that if carbon emissions is allowed according to the current speed increase, to the 2100 world temperatures will probably increase $2{ }^{\circ} \mathrm{C}$ to $4.5{ }^{\circ} \mathrm{C}$. if the global average temperatures more than $1.5{ }^{\circ} \mathrm{C} \sim 2.5{ }^{\circ} \mathrm{C}$, So $20 \% \sim 30 \%$ of plants and animals may face extinction the danger. Droughts, floods and other forms of extreme weather will become more frequent, and threaten food security.Caused by climate warming, melting glaciers and sea level Rise, forcing tens of thousands of coastal areas. The population migration. The figures show, only in 2008 , weather-related caused the sudden disaster about 200000 people displaced. It is estimated that in 2050, 200 million people will be displaced by climate impact. The world has started low carbon economy, low carbon research and practice of the city.The United Nations environment program determine the 2008 .The theme of world environment day (June 5) for the transformation traditional ideas, introduce a low-carbon economy. With long-term city planning for urban development, the influence of the structural effect. The city's material the environment is very difficult to change once they are established, people social and economic life have a profound shadow ring. Build a green traffic system, guide urban industry structure adjustment, promote the development of circular economy, and guide people change the way of life, the application of advanced technology means and by stringent environmental protection measures is the important strategy to realize low carbon city. the city planning theory and method is the key technology of construction the low carbon city. carbon emission calculation of thermal power plant - an overview; impact of climate change on regional economy; design of 
carbon efficient online logistics networks; study on influencing factors of China's carbon emission rights price; study on the multi-target system of building energy efficiency engineering in China; a short review of wastewater biological treatment at low $\mathrm{C} / \mathrm{N}$ ratio; the construction of support system of China's government green procurement; carbon footprint accounting practices in Taiwan; research on EMC promote green commercial buildings form; simulation analysis of a printing factory energy saving; food packaging design exploration with the concept of low carbon; study on model of carbon emission rights allocation among power enterprises; effects of energy prices on energy efficiency in China; the risk analysis of new energy power generation; problem of China's nuclear security supervision system; energy consumption analysis of ship energy system; renewable energy evaluation and plan in Matsu areas; study on heat and power technology of heavy oilfield; short-term power load forecast in electric companies; energy management of industrial installation; the definition and identification of natural resources industries; China's sustainable development, challenges and solutions

\section{The Theory And The Practice Exploration}

What is the cause of global climate change? The IPCC fourth assessment report in 2007, the average global temperature rise since the middle of the 20th century is "very likely" caused by the increase of greenhouse gases produced by human activity. Scientists also reached a consensus in 130 countries and claims that: human-induced global warming. Look from the source of greenhouse gases, the city's population, building, transportation, ind ustry, logistics center is energy intensive and high carbon emissions. According to statistics, the global cities greenhouse gas emissions by $80 \%$ of the world's greenhouse gas emissions. Therefore, the construction of low-carbon cities become the important measure of global climate change crisis. In July 2009 the G8 summit in Italy, and climate change become a hot topic, other than the economic problems in Australia, Brazil, China, Britain, the United States and other 16 countries leaders announced the implementation of low carbon growth plan; In Copenhagen in December 2009, the The multinational leaders put forward the goals to reduce emissions. Urban planning to urban development have a long term, the influence of the structural role. The physical environment of the city is very difficult to change once they are established, on people's social and economic life have a profound impact. Nearly three hundred years since the ind ustrial revolution, the "high carbon" urban development pattern brought huge risks to the further development of the human, there's an urgent need to change the traditional pattern of urban development to deal with the current crisis of global warming. Therefore, to explore an ideal mode of urban development is imminent. To develop the ideal low carbon city, only through the technical means of energy saving and emission reduction is still not enough to solve the problem of carbon dioxide emissions, also need to more diverse standards of urban planning and construction, structure and development pattern from the city on the overall control and reduce carbon emissions. By the means of urban planning, this paper discusses the feasible pattern of the urban land utilization, build a green traffic system, guide the urban industrial structure adjustment, promote the development of circular economy, to guide residents to change the way of life, the application of advanced technology and adopt stringent environmental protection measures, is the important strategy to realize the low carbon city. Low carbon urban planning theory and method is the key technology of low carbon city construction. To slow brought global greenhouse gas emissions to influence, in recent years, energy conservation and emissions reduction, development 
low carbon economy has risen to national strategic height, many countries have established or are being developed to a countries low carbon growth planning. "Mitigation"and" adaptation "is dealing with gas.The main strategic symptom change. "Mitigation" refers to through different means to reduce greenhouse gas emissions, thereby reducing the potential negative impact. Related measures could include promoting low carbon regulations, norms and standards of city construction,Incentives for energy conservation and emission reduction, and encourage the use of the city planning and design of less carbon dioxide emissions and the way of building. "Adaptation" refers to the global warming of biology,natural, geographical system change has produced and cannot avoid exemption under the premise of urban planning from the "adaptation"biological perspective analysis, nature and society change, so as to formulate policies and actions to "adaptation",The negative effects to a minimum.Ericsson joint mandate,pointed out that the physical infrastructure of the 20th century, such as machine field, road, tunnels, Bridges, street lamp,parking field, such as gas station is a high carbon type service facilities, to send show this infrastructure will increase the carbon and investment.In the 21 st century, need to build Information infrastructure, including optical fiber, mobile network base stations and server, through mobile broadband to the light convey information, rely on virtual meetings and Smart Grids, M - the Governance,M - Health, E - Paper, etc. To establish an"Machines to Machines" low-carbon solutions. Many countries are now more and more focus on new energy use of the source. The United States launched the "revival and the United States Reinvestment plan ".Ready to make reusable within three years the output of raw energy multiplier, by 2012Wind and solar power generation of total output $10 \%$.To 2025 , accounting for $25 \%$.

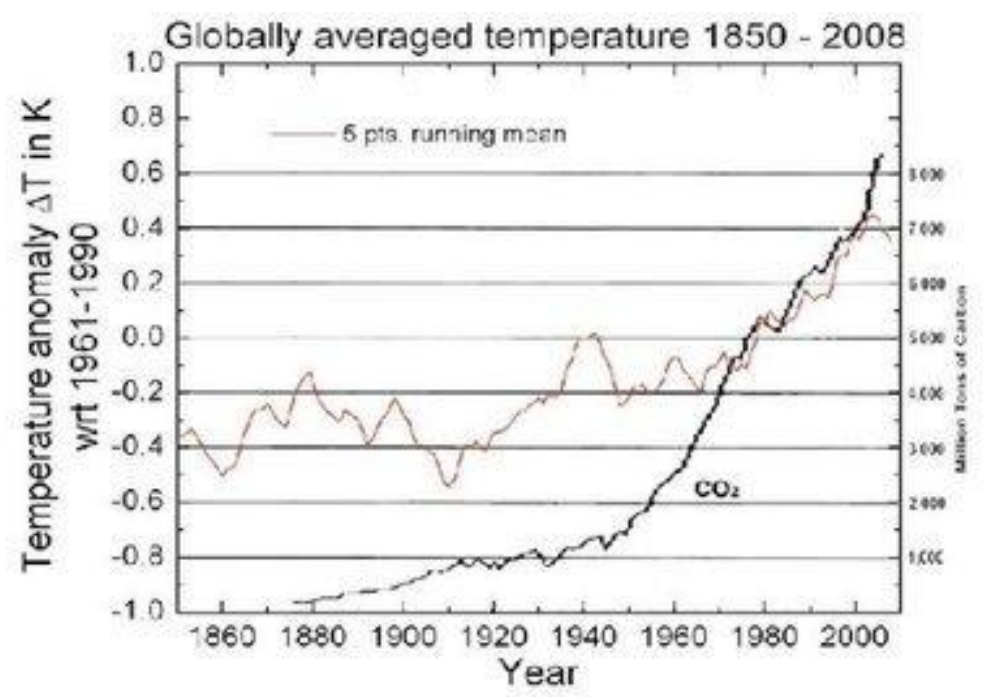

Figure 1 Globally averaged temperature 1850-2008

\section{Research Prospect}

Low carbon city as the current hot issues in the field of planning and research, the existing research results from the relationship between climate change and carbon emissions, low carbon city connotation, space structure, discusses the development strategy and concrete practice, form conclusions to guide the construction of low carbon city plays an important role. As a complex 
proposition, however, remains to be further studied of low carbon city.Existing research results of the basic construction of low carbon city can alleviate global warming crisis issues to reach consensus, and define the connotation of low carbon city is low carbon planning and construction mode, low-carbon lifestyle and low-carbon urban comprehensive operation system. However, to the specific implement low-carbon city construction, there are two aspects need to be further study define the problem of low carbon city. How to define "of low carbon low"? How to determine the source of the "carbon" and composition proportion? What is the specific standard of low carbon city? Is there a quantitative indicators? Different regions, different stage of development of city is the standard for "low carbon" should be how to draw? Especially for a country like China is still in the stage of industrialization of developing countries, the measure of low-carbon cities and developed countries are consistent? about the path of low-carbon city construction. On the macro development strategy at present basically has "slow" and "adaptation" in two ways, their respective adaptability? The complex terrain of China, the vast, the characteristics of regional unbalanced development determines the diversity of the low carbon city development pattern, different regions, different types of cities, the urban construction of low carbon path and temporal what's the difference? In addition, how China under the background of comprehensive transformation of the economic development, the city industry transformation and the building of low carbon industry, the social development combined with the establishment of a low carbon society? The connotation of low carbon city mainly includes three aspects: the first: low-carbon urban planning and construction, including the construction of the spatial structure of low carbon, low carbon city technology application, etc. The second: low carbon city lifestyle, including low carbon consumption concept, enterprise low carbon mode of production, etc. Third: low carbon city operation system, including low carbon economic development model, efficient way of city management, etc.

\section{Conclusions}

China as a developing country, large population, low economic development level, climate condition is complex, The fragile ecological environment. Climate change on the natural ecological system and the economic and social development in China now

The real threat. How to in the process of rapid urbanization through proper means of urban planning clarify city empty between structure, use low-carbon urban planning technology to realize the city function structure of low carbon transformation, to explore suitable for China's national conditions of low carbon city construction implementation mechanism, is the low carbon urban planning needs to foc us on China.

The content of the. Overall, our country has begun the research and practice of low carbon city, but was still in its infancy, a long way to go in the future.

\section{References}

[1] Nicholas Stern. The Stern Review of the Economics of Climate Change[Z]. 2006.

[2] Intergovernmental Panel on Climate Change Fourth Assessment Report[Z].2007 . 
[3]Ron Nyren. Zero-carbon Cities[J].Urban Land, 2008,(6): 56-63.

[4] HM Government. The UK Low Carbon Transition Plan: National Strategy for Climate and Energy[Z]. 2009.

[5] Dennis Pamlin, Suzanne Pahlman,Elaine Weidman. A Five-step-plan for a Low Carbon Urban Development[Z]. 2009. 